\title{
Simulation-Based Design and Optimization of a Stand-Alone Power and Energy System for the High Arctic
}

\author{
Stéphanie Breton ${ }^{1}$, Martin Kegel ${ }^{1}$, Gisele Amow $^{2}$ \\ ${ }^{1}$ CanmetENERGY-Natural Resources Canada, Varennes, Canada \\ ${ }^{2}$ Dockyard Laboratory Pacific-Defence Research and Development Canada, Dartmouth, Canada
}

\begin{abstract}
A thermal and electrical co-simulation was developed to evaluate and assess power and energy (P\&E) systems for remote applications. A stand-alone hybrid system comprised of a solar array, a direct methanol fuel cell and a battery storage system housed in separate insulated enclosures was found to be a suitable option to autonomously operate a data-logging system year-long in the High Arctic. Parametric studies were conducted to optimize the insulation levels of the enclosures as well as the size of the power generation system and the control strategy used for thermal management. The versatile hybrid co-simulation model is able to capture the crucial interactions and trade-offs between thermal and electrical demands. A first version of the system was deployed in the High Arctic during the mid-summer season and successfully operated autonomously for four months providing proof of concept and model validation for the hybrid P\&E system.

Subsequent simulations and parametric studies were run to determine and evaluate additional strategies to extend the autonomous operation of the system. Reducing the power consumption of selected components, increasing the renewable energy generation by installing coldclimate wind turbines, and scaling up the storage capacity by redesigning a new battery pack were found to be effective means of achieving extended operation. Simulation results indicated that the data-logging system could be powered for up to 8 and 12 hours daily during the winter and summer months, respectively, compared to just 30 minutes for the first version of the system with similar fuel consumption. Future work will focus on the simulation-based design of an improved system capable of continuous year-long operation and its validation.
\end{abstract}

\section{Introduction}

Data-logging and communication stations located in arctic regions, in both military and civilian applications, are challenged by harsh environments, isolation and a lack of local energy sources. As a result, nearly all energy used to meet electrical and thermal demands in these regions comes from diesel generators and diesel-fired heaters. In Canada, these remote locations ultimately rely entirely on imported fuels, delivered in bulk by ship or aircraft during the short summer season and stored on-site. This makes them vulnerable to supply disruptions, fuel spills as well as high energy prices. Moreover, all power generation is community-based due to the absence of territory-wide electricity grids. These aspects affect not only the local communities but also government operations.

The importance of reducing this diesel dependency and its potential role in shrinking Canada's carbon footprint is well-recognized. Through Defence Energy and Environment Strategy (DEES, 2017), the Department of National Defence (DND) is tasked to reduce its energy consumption to meet greenhouse gas (GHG) emission reduction targets while maintaining its operational mandates. In line with these goals, Defence Research and Development Canada (DRDC) initiated a project in 2016 to explore alternative and sustainable energy supply options for a remote underwater acoustic array system (UAAS) in the High Arctic (75th parallel North) (DRDC Heard et al., 2016).

The development of an autonomous power and energy (P\&E) system for this application proves particularly difficult. It requires addressing constraints such as remoteness, harsh climate, uncertain weather patterns, wildlife, uninhabited site (one annual visit at most), as well as weight, size, and transport restrictions. Examples exist of autonomous weather stations in remote locations like the Arctic that rely on renewable energy such as small-scale wind and/or solar for year-long power generation. The ultimate challenge resides in being able to meet the unique operational profile of an energyintensive UAAS during the $\sim 130$ days of polar night.

This paper focuses on the thermal and electrical cosimulation of a P\&E system to identify a suitable solution for autonomous operation of the UAAS. First, conventional and alternative technologies for electricity and heat generation considered in the context of this project are reviewed. Then, the development of a preliminary simulation model based on nameplate and estimated power draws of the power and energy system is presented with a discussion on parametric studies conducted to find a suitable design. A comparison of the simulation results to the monitored performance is presented followed by the validation of the P\&E simulation model. Finally, a modified version of the system for extended operating frequency is developed.

While the focus of the paper is on a solution for the High Arctic, the strategy and modelling concepts can easily find application in other remote locations globally. The integration of both thermal and electrical systems in the simulation allows one to assess the trade-offs between the 
electricity requirements and the heating and cooling loads for a given system. Whereas the optimal solution will differ based on the location mainly due to climate, the methodology employed can be generalized for other stand-alone systems with different equipment, schedules, or power and thermal requirements.

\section{Modelling Considerations}

Details of the remote UAAS and site (Gascoyne Inlet, NU) can be found in the DRDC Overview of the Technical Results of the Northern Watch Project Report (DRDC Heard et al., 2016). With the system historically operating only when the site was occupied, an autonomous P\&E system was desired to enable operation throughout the year when the site is mostly unmanned. Further, it was desirable to increase the operating frequency of the system to three times daily, each time for a period of 10 minutes, including 5 minutes for system startup, shutdown, data transmission and computing for real-time analysis. The anticipated peak power draws of the system were estimated to be $\sim 400 \mathrm{~W}$ based on the expected array power draw, inverter inefficiencies, computing loads, and eventual controllers, modems, thermal energy management and data transmission equipment power requirements. Further, the annual energy consumption would be dependent upon thermal energy requirements and standby power draws of the UAAS. As well, the size dimension restrictions for aerial transport for the P\&E system could not exceed $0.25 \mathrm{~m}^{3}$, which had to be factored into the overall design.

\section{Review of power generation options}

Before carrying out simulation studies, a review of existing P\&E supply technologies was conducted to identify a robust solution and predetermine which technologies were feasible. The most obvious power supply option consisted of using a micro diesel generator to power the system throughout the year. Unfortunately, there are no commercially available diesel generators of the required size that offer remote-start capabilities at subzero temperatures. As such, block heaters, furnaces or thermal storage would be required to ensure startup capabilities. Moreover, a significant dump load would need to be installed in order to run the diesel generator at a respectable part-load to avoid excessive wear. This option would also go against DND's efforts to reduce diesel dependency, however, it was investigated only to provide a baseline comparison of the fuel savings provided by other design alternatives.

Photovoltaics (PV) were considered a suitable and robust solution to operate the system during the 235 days when solar energy is available. This technology is known to be reliable in the harshest conditions (NTPC, 2019), with improved efficiency at lower ambient temperatures, and can operate without intervention for decades. However, the solar PV array would need to be coupled with a battery system for storage to supply peak power, provide power during periods of cloudy weather, and most importantly supply power during the months of polar night. One option would be to size the PV system such as to cover the load during the summer months while also charging a large battery bank (lead-acid), which would then be discharged continuously when solar power is not available during the polar nights. While potentially feasible, this approach was rejected because of logistics concerns (expensive, difficult to ship to remote locations, requires a large enclosure with complex thermal management) and risk of performance degradation (selfdischarge, reduced lifetime due to deep discharge). Investing in a large battery bank to be charged only once a year was also deemed financially unattractive. With the solar resource being abundant during periods of midnight sun, a solar PV battery system could be supplemented with an additional low-wattage power generation technology for polar night operation, thus, minimizing the overall size of the system.

Wind energy is also a potentially viable option for supplementary power generation particularly for the polar night period. Considerations for use include operation at extremely low temperatures, wind resource availability, permafrost installation and adequate energy storage.

Another technology with proven operation in cold and remote locations are thermoelectric generators (TEGs), which have no moving parts and convert heat flux from a gas burner into electricity (Gentherm, 2019). Some units as small as $50 \mathrm{~W}$ can be started remotely, but only down to temperatures around $-20^{\circ} \mathrm{C}$ and with limited on/off cycles. A TEG would require large quantities of fuel typically propane or natural gas - because they are characterized by very low efficiencies $(5-10 \%)$, which makes them best suited for applications where the thermal load is significantly higher in comparison to the electrical power requirements.

The last commercially available off-grid power supply technology considered was a direct methanol fuel cell (DMFC) that converts methanol into electricity through a catalytic conversion process (25\% electrical efficiency) (FuelCell Today, 2019). This equipment has the advantage of being maintenance free, sustainable, and able to operate fully autonomously down to $-40^{\circ} \mathrm{C}$. Commercial systems of compact size combining a fuel cell stack with the required thermal management system, control circuitry and fuel delivery components are readily available. A DMFC could provide an adequate complement to solar by switching on to charge the batteries when the solar resource is not available and operating in standby mode with negligible fuel consumption when not needed the rest of the time.

Based on the technology reviews within the geographical, climate constraints and project timelines for installation at the site during the summer period, the most attractive option identified was the use of a hybrid $\mathrm{PV} / \mathrm{DMFC} /$ battery system because it could support the reliable performance required in harsh and remote environments while lowering the energy footprint.

\section{Power and energy system simulation}

\section{Simulation model}

Having determined that a DMFC and solar PV panels coupled with battery storage would be most reliable for 
this stand-alone application, a P\&E simulation model of the proposed system was developed. This flexible model supports the design and assessment of any insulated enclosure and estimates the energy saving potential of different control strategies, increased battery storage and additional renewable energy sources. TRNSYS v.17, a modular and open-source simulation software, was selected due to its ability to model various renewable energy and HVAC systems, and to integrate them with building energy models (Klein et al., 2014). The novelty of this study resides in exploiting the adaptability of TRNSYS to develop a versatile hybrid energy system simulation model, integrating both thermal and electrical systems. The model developed was used to conduct parametric studies to determine optimal design and efficiency strategies to limit methanol consumption.

The P\&E system was divided into two enclosures - one housing the DMFC, and the other the electronic equipment, the batteries and the UAAS. To avoid exposure to high winds and drifting snow, the two enclosures would be located in an unheated, uninsulated building. To ensure functionality of the electronic equipment and sufficient battery capacity, the electronic equipment enclosure would be maintained above $0^{\circ} \mathrm{C}$ with the aid of small electric heaters when necessary. The DMFC enclosure would not be heated as the system is capable of operating down to $-40^{\circ} \mathrm{C}$ with a proper heat trace on the condensate line. To simulate the P\&E system and surrounding conditions, the building housing the enclosures was modelled using Type 56 - a standard multi-zone building model used in TRNSYS. The electronic equipment and fuel cell enclosures were modelled separately, using Type 88 as only one Type 56 component can be included in a given simulation. Type 88 models a simple lumped capacitance single-zone structure subject to internal gains. Furthermore, it assumes an overall thermal conductivity value for the entire structure and it neglects solar gains, which is appropriate since the enclosures are stored inside a building. Its usefulness comes from the speed at which building heating and/or cooling loads can be added to a system simulation. To estimate these loads, Type 88 requires an effective surface area which is determined using equation (1) to properly account for insulation:

$A=2(l w+w h+l h)+2.16 L(l+w+h)+1.2 L^{2}$

where $l, w$ and $h$ are the respective interior enclosure length, width and height, and $L$ is the thickness of the insulating layer (Incopera and DeWitt, 1990). This equation was used to conduct parametric studies in order to determine the minimum thickness of the insulating layer of the insulated electronic enclosure to ensure sufficient methanol fuel is available for year-long operation. Infiltration into the insulated enclosure was modeled with the ASHRAE K1, K2, K3 method (ASHRAE 1997) (Type 571) neglecting the effects of wind driven infiltration due to the indoor location.

The solar PV and battery system was modelled using Type 94 solar PV array component and Type 47 lead-acid storage battery in conjunction with the Type 48 power conditioning component. The latter acts as a charge controller with several functions as illustrated in Figure 1 namely:

1. Distributing DC power from the solar cell array $\left(\mathrm{P}_{\mathrm{PV}}\right)$,

2. Switching on the DMFC and distributing its DC power $\left(\mathrm{P}_{\mathrm{FC}}\right)$ when required,

3. Distributing DC power to and from the battery $\left(\mathrm{P}_{\mathrm{B} \pm}\right)$,

4. Converting DC power to $\mathrm{AC}$ and sending it to the load when required $\left(\mathrm{P}_{\mathrm{L}}\right)$, and

5. Dumping excess power when the batteries are fully charged $\left(\mathrm{P}_{\mathrm{E}}\right)$.

The storage capacity of the Type 47 lead-acid storage battery was modeled at a design temperature of $0^{\circ} \mathrm{C}$. As the battery storage capacity degrades with decreasing ambient temperature, modelling the capacity at $0^{\circ} \mathrm{C}$ was a conservative approach as the batteries would not fall below this temperature during operation. Future improvements to the component model could be incorporated to account for the storage capacity temperature degradation. This approach was not implemented due to time constraints of the project.

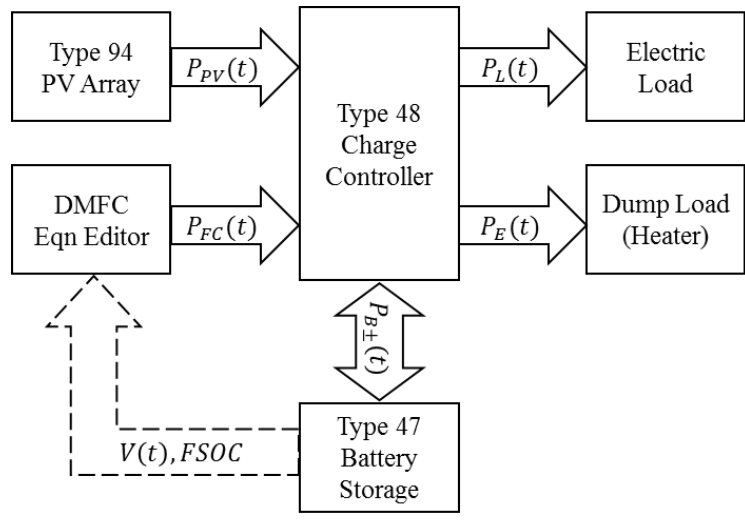

Figure 1 : Charge controller modelling strategy

An extensive effort was undertaken to adapt the charge controller model to off-grid applications. Normally, Type 48 is designed to interact with an electrical grid of infinite capacity, with the possibility of using grid power to meet the load and/or charge the battery storage. The DMFC could therefore not be modelled as the grid as it can deliver a maximum of $110 \mathrm{~W}$. Since there is no parameter in the Type 48 component model to isolate a power and energy system from the grid or to limit the available power capacity of the grid, the model was adapted by resorting to a control strategy that would anticipate when solar power was not sufficient and consequently turn on the fuel cell. In line with the control strategy provided by the fuel cell manufacturer (EFOY, 2019), differential controllers and run-time calculators are used to sense drops in battery voltage $(V(t))$ and fractional state of charge (FSOC) to then switch on the fuel cell to charge the battery bank for a maximum of 24 hours at a time. The DMFC was modelled using a TRNSYS equation editor, with a constant fuel efficiency of $1.1 \mathrm{kWh} / \mathrm{L}$ and an electrical efficiency of $25 \%$. About three times more heat than electricity is generated, which is rejected inside the fuel cell cabinet and exhausted using the fan if required. Additionally, a thermostat was used to turn on the $10 \mathrm{~W}$ 
heat trace on the DMFC condensate line when the building air temperature is below $5^{\circ} \mathrm{C}$.

The simulation model was run with a five-minute time step to estimate the annual electric demand and heating and cooling loads, taking into account anticipated standby power consumptions and internal heat gains from electronic equipment. The TMY weather file from nearby Resolute Bay, NU was used as there is very limited historical weather data available for Gascoyne Inlet, NU.

With the power and energy simulation model, parametric studies could then be run to determine the required electronic equipment enclosure insulation level, the required heating capacity, and the energy saving potential of various efficiency measures. Sizing constraints would need to meet the aerial transport restrictions in addition to the maximum DMFC methanol fuel storage capacity limited to $176 \mathrm{~L}$ (set by the manufacturer).

\section{Simulation results}

To confirm the amount of methanol that would be required to maintain the as-built enclosure above $0^{\circ} \mathrm{C}$ and operate the UAAS as planned, the TRNSYS simulation model was run and parametric studies conducted to evaluate different control strategies and the fuel saving potential of various energy efficiency measures. Due to the size of the electronic equipment for the UAAS and space required for the batteries, a standard electrical cabinet enclosure meeting the transport size constraints was specified and insulated from the inside to minimize heat losses. A parametric analysis on insulation thickness was performed with eventual insulation size selected based on maximum thickness permissible due to the electronic equipment space requirements. Initial simulations therefore modelled the cabinet with $152 \mathrm{~mm}$ of polyisocyanurate (polyiso) insulation and a $30 \mathrm{~W}$ electric heater to maintain the enclosure above $0^{\circ} \mathrm{C}$ yearlong. Heat gains from the equipment and thermal capacitance were all included in the model. During the warmer summer months, a cooling fan would draw in cooler air to bring the electronic insulated cabinet below $25^{\circ} \mathrm{C}$. Summer temperatures at the location rarely exceed $10^{\circ} \mathrm{C}$, so no vapour compression cooling system was deemed necessary. The UAAS would operate for 10 minutes every 8 hours on a daily basis to process and transmit data. During non-operation periods, much of the equipment would be in standby mode with very low power draws.

Estimates for this initial design indicated that the DMFC would require close to $195 \mathrm{~L}$ of methanol to operate the entire system over the year. Table 1 summarizes the anticipated annual electricity requirements, annual

Table 1: Simulated power and energy requirements of UAAS for various scenarios

\begin{tabular}{ccccc}
\hline Scenario & $\begin{array}{c}\text { Annual Electricity } \\
(\mathbf{k W h})\end{array}$ & $\begin{array}{c}\text { Annual Electricity } \\
\text { from Fuel Cell (kWh) }\end{array}$ & $\begin{array}{c}\text { Polar Night Heating } \\
\text { Electricity (kWh) }\end{array}$ & $\begin{array}{c}\text { Annual Methanol } \\
(\mathbf{L})\end{array}$ \\
\hline Initial design & 324 & 214 & 103 & 195 \\
$\# 1$ & 316 & 204 & 95 & 185 \\
$\# 2$ & 309 & 200 & 88 & 182 \\
$\# 3$ & 306 & 190 & 88 & 173 \\
$\# 4$ & 279 & 174 & 61 & 158 \\
\hline
\end{tabular}

electricity production requirements from the fuel cell, heating requirements during the polar night and the total amount of methanol required for this scenario as well as the scenarios to be considered next. With a DMFC fuel cell efficiency of $1.1 \mathrm{kWh}$ of electricity produced per litre of methanol, $20.8 \mathrm{kWh}$ of electricity required from the fuel cell would need to be reduced annually to be within the fuel storage capacity limit (10\% reduction).

\section{Parametric run \#1: Infiltration reduction}

The first parametric run examined the impact of making the enclosure more airtight. The ASHRAE K1, K2, K3 method is typically used for buildings and thus the equation has a constant air infiltration rate. With an insulated enclosure, if care is taken in sealing the cabinet, the constant infiltration rate is likely not applicable and only differences in temperature would induce infiltration. Running the simulation omitting the constant infiltration rate component resulted in $10 \mathrm{~L}$ methanol savings $(185 \mathrm{~L}$ total), still above the $176 \mathrm{~L}$ limit (Table 1).

\section{Parametric run \#2: Lower setpoints and staged heaters}

To save some energy used for heating, the use of two different sized heaters was evaluated, with each heater staged at a different temperature setpoint. The parametric study evaluated a $10 \mathrm{~W}$ heater set to $3^{\circ} \mathrm{C}$ (stopping at $10^{\circ} \mathrm{C}$ ) and a $30 \mathrm{~W}$ set to $0^{\circ} \mathrm{C}$ (stopping at $7^{\circ} \mathrm{C}$ ) (thermostats had a $7^{\circ} \mathrm{C}$ temperature dead band). As such, instead of maintaining the enclosure at $7^{\circ} \mathrm{C}$ with one large heater, a smaller heater could be used first to maintain an enclosure temperature closer to $3^{\circ} \mathrm{C}$ and then a supplemental heating capacity added if the $10 \mathrm{~W}$ heater is unable to maintain the enclosure temperature above freezing. This resulted in $3 \mathrm{~L}$ of additional methanol savings (182 L total) (including the savings from parametric run \#1), which is closer to the annual target of $176 \mathrm{~L}$ (Table 1).

\section{Parametric run \#3: Additional solar PV panels}

The next parametric study assessed the potential methanol savings achievable through an increase in the solar power production by adding two more identical south-facing solar PV panels $\left(265 \mathrm{~W}_{\mathrm{p}}\right)$ to the system. While sufficient electricity is generated during the summer periods, the additional solar PV panels could reduce the need of the DMFC during the shoulder periods close to the polar night, when the sun is partially blocked by the local southfacing hill and cliff. From the simulation results, increasing the solar PV array in addition to the modifications mentioned in parametric runs \#1 to \#3 would be a viable option to reduce the annual methanol consumption below the maximum $176 \mathrm{~L}$ (Table 1). 


\section{Parametric run \#4: Additional insulation}

Lastly, to further reduce the transmission of thermal energy through the array enclosure walls, the possibility of adding insulation to the exterior of the enclosure was also considered. It would not be possible to increase the insulation level inside the enclosure because of lack of space. A parametric run with an additional layer of $51 \mathrm{~mm}$ of polyiso around the outside of the enclosure was run. The results shown in Table 1 highlight a substantial 30\% reduction in electricity consumed for heating during polar night, which would lead to $15 \mathrm{~L}$ of methanol savings compared to the previous scenario. Unfortunately, this option was not practically viable due to the additional complexity and time associated with adding the external insulation while on site. The insulation layer could not be installed prior to shipping the enclosure because of tight size constraints.

The system simulation results for the final version of the power and energy system to be installed, which includes the first three improvements described above, are presented in Figure 2. The solar array comprised of four PV panels is able to deliver sufficient power to cover the electrical load during six months (from April to September) when the heating load is at its minimum. Heating is required almost throughout the year, even during temperate summer months, because of the fuel cell heat trace that is almost continuously. With the implemented operating schedule, meaning the electronic equipment cycling on and off three times daily, only about $40 \%$ of the total energy $(130 \mathrm{kWh})$ is consumed by the data-logging system. The rest of the energy $(176 \mathrm{kWh})$ is dedicated to auxiliary equipment such as the electric heaters and cooling fans. Operating a system sensitive to temperature extremes in a frigid environment proves to be a challenge in terms of thermal management. The fuel cell is estimated to operate for a total of 1,700 hours over the year with an annual methanol consumption of $173 \mathrm{~L} \mathrm{-}$ compared to over 2,000 L of fuel had the system been powered by a diesel engine generator. This is within the maximum annual available quantity of methanol (176 L) for the fuel cell, so this option was selected as the final design for the first version of the remote power and energy system. As shown in Figure 2, there is a considerable amount of excess solar energy (denoted "Excess Renew.") which could not be harvested (over $80 \%$ of total energy from PV) because it could not be stored in the batteries at the time of availability.

\section{Existing system design and operation}

In August 2017, the first version of the P\&E system was installed in the High Arctic and tested over a year until the next annual site visit. The final version of the system installed, however, differs slightly from the design described above. To meet the desired operating frequency of the UAAS, the electronic equipment and batteries were placed in an airtight insulated enclosure with $10 \mathrm{~W}$ and $30 \mathrm{~W}$ staged heaters. The excess solar PV electricity was rejected through an electric resistance heater inside the building, although not providing noticeable savings, because this was embedded in the solar charge controller installed. The main difference between the proposed design and the as-built system is that only two solar panels were installed because of the tight timeline and logistical constraints of the project. According to the parametric studies conducted previously, this modification in the design would lead to an annual fuel consumption closer to $182 \mathrm{~L}$ (parametric run \#2). This was deemed acceptable for the first version of the system since the weather file used in the simulation corresponds to a colder and more northern location than the actual site, which presumably lead to an overestimation of the heating requirements and an underestimation of the available solar energy during shoulder periods. Further model refinements would be done following the validation with real-time operation.

The UAAS was successfully powered until the third week of December 2017 providing proof of concept for the autonomous hybrid P\&E system design. A subsequent visit to the remote site in July 2018 allowed for a diagnosis of the P\&E system and for subsequent improvement suggestions. Important observations made during the visit helped determine why the system did not operate throughout the entire year. Firstly, the solar charge controller was switched off at some unknown time (by what was thought to be a bear), which shortened the period over which solar power was available to charge the batteries and led to an increase in DMFC methanol consumption. In addition to this, an issue with the fuel cell configuration prevented the system from accessing the fourth methanol fuel cartridge thereby reducing the available fuel to $116 \mathrm{~L}$. Temperature measurements and

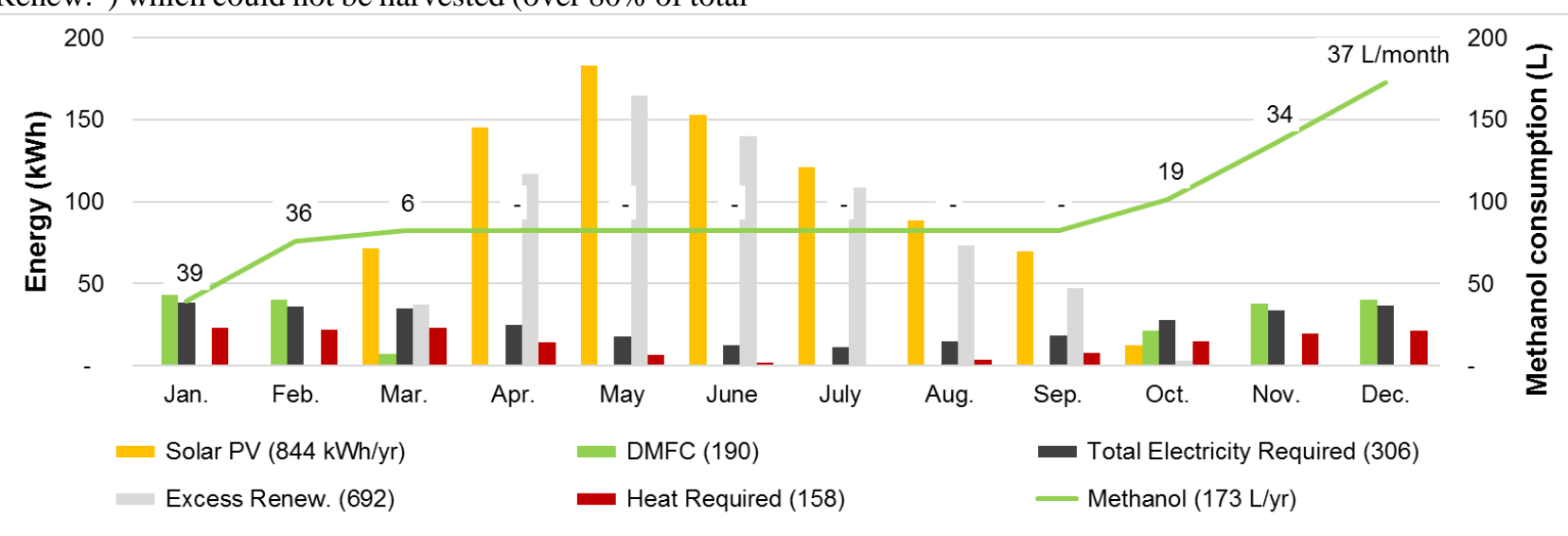

Figure 2: Monthly energy generation and consumption for the first version of the power and energy system 
power draws of various equipment were also recorded during the 2017 operation. The collected temperature and power data were used to correct and validate the simulation models, especially highlighting that the antifreeze operation of the fuel cell had a significantly greater impact on the fuel consumption than initially anticipated. This is highlighted with the simulation model predicting that only $80 \mathrm{~L}$ would be required to power the UAAS system until the time in December when the system stopped working, well below the $116 \mathrm{~L}$ of available methanol. The antifreeze operation of the DMFC was confirmed with the temperature measurements of the fuel cell cabinet. It indicated that the fuel cell operates for approximately 5 minutes every 2 hours when it is not being used to charge the batteries. This allows heating up the fuel cell stack and preventing it from freezing. The control strategy of the DMFC was modified in subsequent versions of the simulation model to account for the additional fuel consumption associated with the antifreeze mode.

To compare with the actual system operation, an updated simulation model was run. The antifreeze mode was modelled and the PV array assumed to be turned off in mid-September. Moreover, the power draw of the equipment was modified to match the measured values, rather than using the nameplate power requirements. The methanol consumption from August until the end of December is then predicted to be $110 \mathrm{~L}$, which is comparable to what was actually used by the system $(112 \mathrm{~L})$ when taking into account uncertainty in the ambient environmental data. Had the system been able to operate as expected, the fuel required to power the system year-long is estimated to be $200 \mathrm{~L}$, which would have enabled operation through the month of February.

\section{Future system for extended operation}

Following the successful deployment of the first version of the P\&E system in the High Arctic, it was decided to investigate upgrading the system for extended and remotely controlled operation. Simulation-based assessment and optimization were used to redesign the system to achieve longer and/or more frequent autonomous operation. To this end, strategies to reduce power requirements, to integrate additional renewable energy, to increase the storage capacity and to vary operational schedules were undertaken and are discussed below.

\section{Reduction of the energy consumption}

Prior to evaluating the potential of adding renewable energy technologies or batteries, energy efficiency measures were assessed. A major energy reduction opportunity was identified at the level of the dataprocessing equipment, more specifically in the data collection unit (DCU). Modifications to the DCU allowed for a twenty-fivefold reduction in power draw - from $155 \mathrm{~W}$ down to $6 \mathrm{~W}$. Fuel savings from this change are negligible under the original operation strategy (operating 3 times daily for a period of 10 minutes) because the reduction in heat gains from the electronic equipment would have to be compensated by additional auxiliary heating. However, the savings become significant if the DCU is to be left on at all times, which would ensure easier custom control and continuous data transfer. As such, all subsequent simulations were run assuming that the DCU and the transmission and control equipment are powered constantly. Only the most energy intensive data acquisition component would operate periodically, either on demand or according to predetermined schedule.

\section{Integration of additional renewable energy}

As mentioned previously, the biggest challenge in powering the data-logging system is to do so during polar nights. This $\sim 130$ day period is characterized by solar irradiation too low or absent to provide any PV power, and temperatures averaging $-35^{\circ} \mathrm{C}$, which are associated with high heating loads. It is therefore interesting to consider harnessing wind power, which is omnipresent throughout the year to help improve the system autonomy during polar nights. A review of commercially available wind turbines was undertaken to assess and confirm their suitability for this project and two $400 \mathrm{~W}$ wind turbines with proven operation in cold weather were selected.

Wind power was integrated in the simulation model using the wind energy conversion system (WECS) Type 90 TRNSYS component. Hourly wind speed and wind direction data from the Resolute Bay airfield were used, because very limited historical weather data is available for the exact remote location. Based on a power versus wind speed characteristic curve obtained from the manufacturer, the model estimates the power output while taking into account the impact of air density and wind speed changes with height. The total annual energy production, assuming $10 \%$ of losses due to transmission and wind data uncertainty, was estimated to be $655 \mathrm{kWh}$. The monthly wind power production was approximately constant, averaging $55 \mathrm{kWh} /$ month during both the winter and the summer seasons. Daily output showed more variability, with an estimated 70 days without any power produced by the wind turbines.

Several simulations were run with the new, less energyintensive DCU and the integration of the two wind turbines in order to determine the maximum viable extended operation. To maximize the total operation time over the year, seasonal operating schedules were determined to make the most of the solar power available during the midnight sun (24-hr daylight). The maximum daily frequency of operation at the desired 10-minute interval is 36 times over the winter (mid-October to midMarch), and 48 during the summer. There is a limit to the extension of the system operation because the $110 \mathrm{~W}$ fuel cell does not provide enough power to simultaneously meet the load (up to $200 \mathrm{~W}$ with the entire system on) and charge the batteries, hence the system needs regular downtime or to be coupled to a larger fuel cell.

Under this new operational strategy, approximately $85 \%$ of the total annual energy use is dedicated to the datalogging system, while the rest is used by the auxiliary equipment. The thermal management of the insulated enclosure (to prevent the batteries from freezing) is now mostly met by the heat rejected by the electronic 
equipment operating continuously rather than by auxiliary electric heating. This leads to a near $60 \%$ reduction in heating load. The fuel cell is now operating every month of the year, which is a consequence of the modified DMFC model to account for the antifreeze mode. The fuel cell is estimated to operate for a total of 1,700 hours over the year, $15 \%$ of which correspond to operation in the antifreeze mode. This results in approximately $3 \mathrm{~L}$ of methanol being consumed monthly during the summer, for a total of $174 \mathrm{~L}$ for the full year. An important observation is that there is significant excess energy produced by the solar panels and the wind turbines. Thus, by storing more of this renewable energy, further fuel savings could be achieved or the operation frequency increased.

\section{Increase of the electrical storage capacity}

Boosting the energy storage capacity was deemed necessary so as to capture more of the excess wind and solar energy and make it available when the demand is there. Upgrading an existing system comes with its constraints; it is challenging to integrate new batteries in existing, custom, restrained enclosures. The option of housing additional batteries in the existing fuel cell cabinet was assessed through simulation. However, the poor cabinet insulation and the high sporadic bursts of waste heat discharged from the fuel cell $(\sim 300 \mathrm{~W})$ are not a good combination for thermal management. Designing a new custom insulated box dedicated to the new batteries proved to be a better alternative. Similarly as to what was done for the initial design of the electronic equipment insulated enclosure, parametric studies were run to optimize the insulation of the battery box and the number and type of batteries. The insulation material selected was polyiso whereas the thickness of the insulation layer was a parameter to be optimized. The upgraded energy storage system would still be comprised of AGM valve regulated lead acid batteries, but of larger capacity. A dozen batteries were selected based on their capacity (Ah), size (volume), and low temperature performance, and compared through annual system simulation.

Using the P\&E simulation model developed, parametric studies on the various battery types and thermal energy requirements were conducted to find the optimal solution. More precisely, the parametric studies performed showed that the benefit of additional storage capacity might be offset by an increase in heating loads to keep the batteries from freezing. To store more electrical energy, a higher number of batteries and/or larger batteries would be required. These would have to be stored in a larger casing or in a lesser insulated one to provide more battery installation space, which would be detrimental from a thermal management point of view.

The TRNSYS Type 88 component model was used to simulate the battery box. The building surface area and volume, the building loss coefficient and the building capacitance were modified to reflect the different insulation and battery configurations. The optimal combination studied was comprised of three 260-Ah AGM batteries, contained in a rotomolded polyethylene case, with $76 \mathrm{~mm}$ polyiso insulation on all sides and $152 \mathrm{~mm}$ on the top and bottom. From anticipated internal gains and heat losses, it was estimated that a $30 \mathrm{~W}$ electric heater would be necessary in order to keep the batteries above $0^{\circ} \mathrm{C}$; temperature at which the available capacity of the batteries are reduced to $85 \%$ of their rated conditions.

Annual simulations of the UAAS with additional battery storage were run to estimate the maximum 10-minute operating frequency. The results suggest that during the winter the system can be operated 48 times and during the summer period 72 times daily. The detailed monthly energy and fuel consumption for this improved design under 10-minute operation are presented in Figure 3. For the scenario displayed, a $27 \%$ increase in electricity requirements can be observed - due partly to higher heating loads - while the fuel consumption is reduced especially during transition from summer to winter.

\section{Conclusions and future work}

This paper discussed the design and optimization of a hybrid power and energy system through the use of thermal and electrical co-simulation for an arctic-based application. A holistic simulation model was developed in TRNSYS and used to assess alternative technologies to replace the diesel generators and diesel-fired heating devices typically used for remote applications. Taking into account the logistical and technical constraints associated with the project location in the High Arctic, review of existing power supply options was carried out.

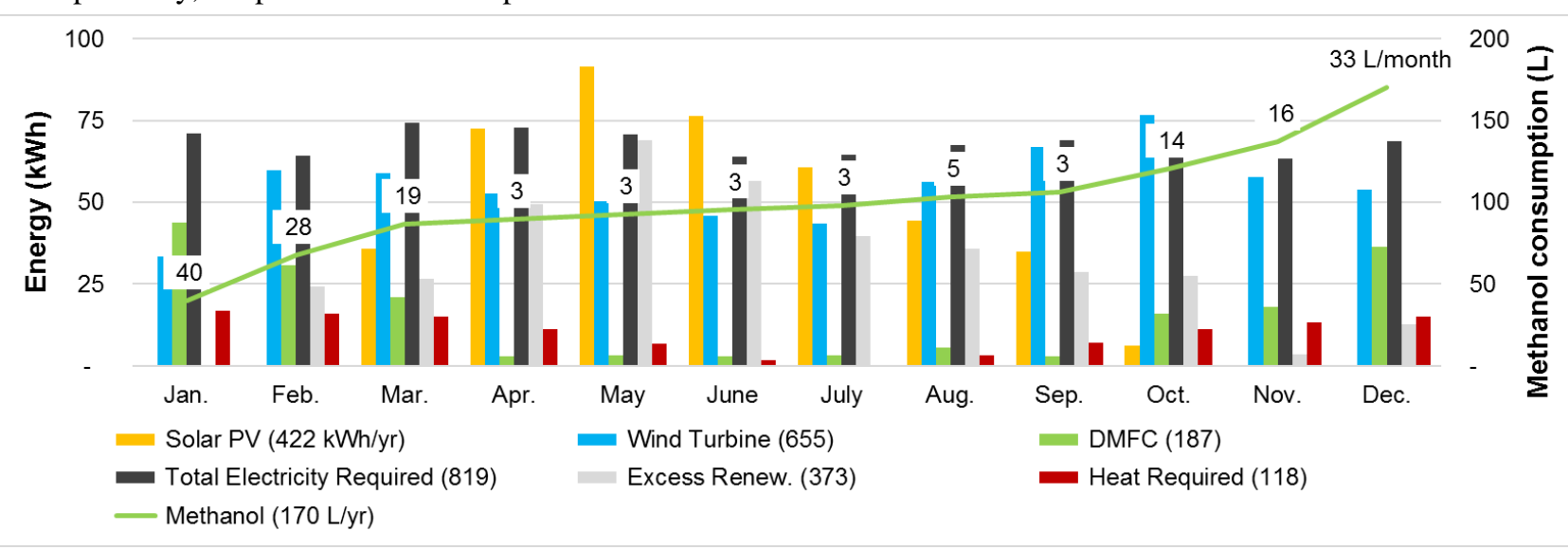

Figure 3: Monthly energy consumption with new DCU, wind turbines and new battery system 
A system comprised of solar photovoltaic panels, a direct methanol fuel cell and a lead-acid battery storage system was identified as being a viable combination to sustainably, autonomously and reliably operate the underwater acoustic array system (UAAS) three times daily for 10 minutes over an entire year. A fixed building and two indoor insulated enclosures were modelled in TRNSYS to accurately simulate operating conditions and estimate the HVAC requirements to satisfy the minimum operating temperature of various equipment. Through the simulation model, the required insulation thickness and enclosure size were optimized and several parametric studies were conducted to improve the energy efficiency of the system and to ensure that the annual methanol consumption was within the limit of $176 \mathrm{~L}$.

After several months of operation, the simulation model was validated with measured performance data and then used to assess different measures to extend the operation period and frequency of the UAAS. As part of the extended operation, a wind turbine component was integrated into the energy model to evaluate the energy generation potential. With the addition of two coldclimate $400 \mathrm{~W}$ wind turbines, the simulation model estimated that the system could operate up to 6 hours a day during the winter and 8 hours a day during the summer when compared with 30 minutes daily under the previous operation strategy for similar fuel consumption. Simulation results highlighted the presence of significant excessive renewable energy that could not be stored or used at the time of availability, which motivated the redesign of the system with increased storage capacity. By integrating both thermal and electrical systems in the simulation model, parametric studies could be run to optimize the new battery pack (size, capacity) and its designated enclosure (insulation level). Under the final design with 780 Ah of battery capacity, the hybrid power and energy system could increase the provision of power for the UAAS to 8 and 12 hours during the winter and summer months, respectively.

Future work will look at redesigning the system to achieve year-long continuous autonomous operation. Preliminary studies have indicated that increasing the solar array size could contribute to powering the system continuously during the summer. However, with the present UAAS power draws, the inclusion of wind energy as well as a larger capacity fuel cell would be required to run the system constantly through the winter, which will be investigated.

Lastly, this simulation methodology can be used to design hybrid power and energy systems for military or civilian applications with different equipment, schedules, and power draws in any climate. The simulation-based design process and use of parametric studies are replicable, and the strategy implemented to adapt the charge controller can prove useful for the assessment of other off-grid systems.

\section{Acknowledgement}

The authors acknowledge the financial and logistics support under the DRDC "Canadian Arctic Underwater
Sentinel Experiment (CAUSE)" project. The authors also acknowledge the data, expertise and coordination made available by Derek Clarke, Garry Heard, Chris Browne, Al Tremblay and Jim Milne from DRDC-Atlantic and Eric McDonald from CanmetENERGY-Varennes.

\section{References}

American Society of Heating, Refrigeration \& AirConditioning Engineers (ASHRAE) (1997). ASHRAE Fundamentals. Atlanta (USA).

Defence Energy and Environment Strategy (DEES). (2017) Minister of National Defence, Government of Canada. Available at: https://www.canada.ca/en/ department-national-defence/corporate/reportspublications/dees.html. Last Accessed January 2019.

EFOY. (2019). EFOY Pro 2400. Available at: https://www.efoy-pro.com/en/efoy-pro/efoy-pro2400/. Last Accessed April 2019.

Fuel Cell Today. (2019). DMFC. Available at: www.fuelcelltoday.com/technologies/dmfc. Last Accessed January 2019.

Gentherm. (2019). Thermoelectric Generators (TEGs). Available at: www.genthermglobalpower.com/ products/thermoelectric-generators-tegs. Last Accessed January 2019.

Greening Government Strategy (GGS). (2017) Government of Canada. ISSN: 978-0-660-24164-7 https://www.canada.ca/en/treasury-board-secretariat/ services/innovation/greening-government/strategy. html. Last accessed January 2019

Heard, G. J., McArthur, B., Inglis, G. (2016). Overview of the technical results of the Northern Watch Project (Scientific Report DRDC-RDDC-2016-R115). Defence Research and Development Canada (DRDC).

Incropera, F. P., \& DeWitt, D. P. (1990). Introduction to heat transfer. J. Wiley. New York (USA) .

Klein S.A. et al., 2014. TRNSYS 17 - User manual. University of Wisconsin-Madison, Solar Energy Laboratory, Madison (USA).

Northwest Territories Power Corporation (NTPC). (2019). Colville Lake Solar Project. Available at: www.ntpc.com/smart-energy/how-to-save-energy/ colville-lake-solar-project. Last Accessed April 2019. 